\title{
O DESPERTAR DO SONHO DOGMÁTICO ${ }^{1}$
}

Orlando Bruno Linhares ${ }^{2}$

- RESUMO: Neste artigo argumento contra a interpretação muito difundida segundo a qual o ano de 1769 representou um marco na formação da filosofia transcendental e a Dissertação de 1770 corresponde ao primeiro texto crítico. O objetivo deste artigo é investigar a origem das antinomias nas Reflexões da década de 1770. Não se trata de esboçá-las, pois sobre elas Kant é reticente nesse período. Elas são objeto da atenção dele somente às vésperas da redação da Crítica da razão pura. Eu me ocupo apenas com alguns dos elementos que possibilitarão sua formulação e solução na Crítica da razão pura.

- PALAVRAS-CHAVE: analítica transcendental, dialética transcendental, razão, entendimento e antinomia.

\section{Introdução}

O objetivo deste artigo é investigar a origem das antinomias nas Reflexões da década de 1770 e o papel que elas desempenham na gênese da Crítica da razão pura.

A tese em que a grande luz de 1769 se refere à descoberta da idealidade e da subjetividade do espaço e do tempo é motivada pela tomada de consciência do problema das antinomias, e dividiu os intérpretes em dois grupos. De um lado estão aqueles que, ao defenderem essa tese, procuram na R 5037, ${ }^{3}$ nos Prolegômenos a toda metafísica futura e na carta a Christian

1 Artigo enviado em 05/2005; aprovado para publicação em 07/2005.

2 O autor é doutor em Filosofia pelo DF-IFCH-UNICAMP e professor do Curso de Filosofia da Universidade Mackenzie; oblinhares@uol.com.br.

3 A letra R refere-se às Reflexões, que são notas feitas por Kant no verso de cartas, em folhas avulsas e no seu exemplar da Metafísica de Baumgartem, o qual servia de base para suas aulas de me- 
Garve de 21 de setembro de 1798 os argumentos para a sua comprovação. Alguns dos seus principais representantes são Benno Erdman (1878), Hans Vaihinger (1976), Ernst Cassirer (1985), Leo Robson (1924) e H. J. de Vleeschauwer (1938 e 1976). Mas se eles estão de acordo sobre o problema que deu origem à filosofia crítica, discordam, contudo, sobre a qual influência Kant estava sujeito nesse momento. De outro lado estão, por exemplo, Klaus Reich (1958), J. Fang (1967) e Joseph Schmucker (1974), que defendem que o despertar do sonho dogmático se dá após a redação da Dissertação.

A questão sobre o que acendeu em Kant a grande luz de 69 recebeu de Erdmann uma resposta que durante muito tempo foi tomada como definitiva. A novidade da sua interpretação consiste em fazer depender a origem do criticismo do problema das antinomias. Erdmann fundamenta a sua argumentação na R 5037, em que Kant diz:

Se eu conseguir convencer que é necessário suspender a elaboração desta ciência até que sobre este ponto se tenha decidido, então este escrito terá atingido seu propósito.

No começo vi esta doutrina como em uma penumbra. Eu tentei com toda seriedade demonstrar proposições e seu contrário, não para fundar uma doutrina da dúvida, mas porque eu queria descobrir onde se encontrava a ilusão do entendimento que eu suspeitava. O ano de 69 me trouxe uma grande luz. (R 5037, Ak. XVIII, p. 69)

Nessa Reflexão, escrita, segundo Erich Adickes, entre 1776 e 1778, Erdmann crê que muitos dos elementos, presentes no capítulo referente à antinomia da razão pura, elaborado em 1781-7, já tinham sido pensados por Kant em 1769. Erdmann identifica a "doutrina" com a antinomia da razão pura e "a grande luz de 1769" é tanto a teoria do espaço e do tempo como formas a priori da intuição sensível, que resolve o problema antinômico, quanto a distinção das faculdades de conhecimento em sensibilidade e en-

3 tafísica. As Reflexões foram publicadas por Adickes nos volumes XVII e XVIII das obras completas de Kant da Academia de Ciências de Berlim. A análise das Reflexões apresenta dificuldades numerosas e de diferentes ordens. Tratando-se de notas pessoais, a preocupação de Kant não é com o leitor nem com a forma literária do texto. Embora os manuscritos se constituam num rico material, sua redação é problemática: fragmentada, pois formada de pequenos papéis avulsos. Muitas vezes, vários desses fragmentos apresentam teses contraditórias. Diferentemente dos textos publicados, Kant não elabora um esquema claro e rigoroso. A construção das frases é, muitas vezes, confusa. Em algumas notas há omissão de uma ou mais palavras nas frases e algumas frases são interrompidas. Em outras, palavras ou frases são simplesmente reunidas. Em algumas notas, Kant é alusivo, noutras apenas sugere um meio de resolver o problema formulado, mas não desenvolve uma solução. Alguns termos são indecifráveis ou, pelo menos, de difícil compreensão. Também o autor não tem ainda uma terminologia fixa. Estabelece, em muitas Reflexões, distinções conceituais importantes para a solução de cada problema, mas em seguida as renuncia, mudando-as por outras de acordo com as dificuldades do momento. Também a dificuldade de periodização das Reflexões torna a exposição difícil. 
tendimento. O objetivo de "demonstrar proposições e seu contrário" referese às teses e às antíteses das antinomias cosmológicas. "A ilusão do entendimento" refere-se à ilusão transcendental. Também já está concebido o método cético (Erdmann 1878, pp. LXXXVI-LXXXVIII).

Segundo Erdmann, Kant descobre o problema das antinomias ao conceber o espaço e o tempo como realidades absolutas ou como relações entre as substâncias. A necessidade de resolver o conflito da razão consigo mesmo levou-o à teoria da idealidade e subjetividade do espaço e do tempo e ao caráter fenomênico dos objetos em 1770, pois essa teoria evita que a razão demonstre com todo o rigor duas proposições contraditórias, sem poder decidir-se definitivamente por uma delas. Ao estudar as origens do criticismo, Erdmann busca o motivo decisivo da mudança da concepção realista do espaço, de 1768, para a idealista, de 1770, e o encontra no problema do conflito da razão consigo mesma, que será sistematizado, em 1781, sob o título de antinomia da razão pura. Erdmann estabelece uma relação necessária entre o problema das antinomias e a doutrina da idealidade do espaço e do tempo em 1769-70, pois ele julga provável que a afirmação de que o espaço precede as coisas resultou, em 1768, no dilema relativo à divisibilidade da matéria, problema que Kant imaginava ter resolvido na Monadologia física ao conciliar a metafísica e a geometria, isto é a substancialidade da matéria com a divisibilidade infinita do espaço.

Também segundo essa interpretação, a Correspondência entre Leibniz e Clarke, publicada em 1768, foi estudada por Kant às vésperas da redação da Dissertação. Vaihinger (1976, pp. 436-530) e Cassirer, seguindo os passos de Erdmann, buscam nas Reflexões as evidências de que Kant tomou consciência do problema das antinomias ao ler, no período de 1768 a 1770, as correspondências entre Leibniz e Clarke. De acordo com o esquema feito por Cassirer, utilizando a edição de Erdmann, temos: as R 1416, 1417 e 1426, que analisam o problema do começo do mundo no tempo, correspondem à quinta carta de Leibniz, § 55; a R 1557, que analisa o problema do movimento do cosmos, corresponde à quinta carta de Leibniz, § 52; a R 1423, que analisa as dificuldades relacionadas com o lugar do mundo e o tempo antes do mundo, corresponde à terceira carta de Leibniz, § 5, e também à quarta carta de Leibniz, § 13 e seguintes; a R 1458, que discute o problema da divisibilidade "lógica" e não "real" do espaço absoluto, corresponde à quarta réplica de Clarke, §§ 11 e 12 (Cassirer 1986, p. 577, nota. 24).

Para apoiar a R 5037, os defensores dessa tese mencionam dois relatos autobiográficos de Kant, em que as referências ao papel das antinomias na gênese da filosofia crítica são precisas. Nos Prolegômenos, Kant antecipa parte do que escreverá em 1798 a Garve: "Este produto da razão pura no seu uso transcendente é o fenômeno mais notável, aquele que, entre todos, age mais poderosamente para despertar a filosofia do seu sonho dogmático e a 
impele para a obra árdua da crítica da própria razão" (Kant 1783, p. 338). E na carta a Garve de 21 de setembro de 1798, escreve:

Não é o exame da natureza de Deus, da imortalidade etc. que foi meu ponto de partida, mas a antinomia da Razão Pura: "O mundo tem um começo. - O mundo não tem um começo etc. (...) O homem é livre - contra: Não há liberdade. Mas tudo, inclusive o homem, está submetido à necessidade natural." É esta antinomia que me despertou do meu sonho dogmático e me conduziu à Crítica da razão pura a fim de suprimir o escândalo da contradição da razão consigo mesma. (Kant 1991, p. 705)

Mas se, segundo essa interpretação, o problema das antinomias apresenta um caráter inovador já em 1769-70, o sistema dos quatro pares de teses contraditórias só foi elaborado depois de 1774-5, após ser encontrado, no Duisburg Nachlass, o fio condutor para a descoberta de todos os conceitos puros do entendimento. Kant pôde demonstrar por que são essas e não outras as antinomias, por que há exatamente essas categorias e não outras. Para Vleeschauwer a tese de Erdmann é aceitável com algumas restrições: "o problema das antinomias desempenhou um papel considerável na gênese da Dissertação", mas ele não o considera o elemento determinante, pois é "estranho e desconcertante que a Dissertação não faça um uso maior e, sobretudo, mais claro dessa doutrina" (Vleeschauwer 1976, pp. 148-9).

De outro lado, a tese de Erdmann motivou inúmeras críticas, com as quais estou de acordo. Klaus Reich ao negar o papel das antinomias na elaboração da doutrina da idealidade e subjetividade do espaço e do tempo na Dissertação, apóia sua interpretação, em parte, nos mesmos relatos autobiográficos de Kant, analisados por Erdmann, negando uma interpretação, que durante muito tempo foi aceita como uma verdade inquestionável.

A R 5037, na qual Erdmann se apóia para fundamentar a sua interpretação, não é clara e precisa sobre o que Kant quer dizer nesse momento, e por isto não é possível afirmar que muitos dos elementos que constituirão o capítulo da antinomia da razão pura já estão presentes nela. "Este ponto" referido no $1^{\circ} \S$ da $\mathrm{R} 5037$ é, segundo Klaus Reich, a pergunta pela possibilidade dos juízos sintéticos a priori (Reich 1958, p. XII). Embora Klaus Reich não se ocupe com as Reflexões da década de 1770, verifica-se já na primeira metade desta década (após a redação da carta a Marcus Herz, de 21 de fevereiro de 1772, em que é formulado o problema do mistério da metafísica nos seguintes termos: "Em que fundamento assenta a relação entre o que chamamos a representação e o objeto"? [Kant 1991, p. 94] ) que a preocupação central de Kant é com a demonstração da possibilidade dos juízos sintéticos a priori. Na R 4634, Kant escreve:

Todos os juízos analíticos podem ser conhecidos a priori e é sintético o que pode ser conhecido somente a posteriori. É porque os juízos propriamente empíricos 
são sintéticos. Mas há, contudo, juízos, cuja validade parece estabelecida a priori e são também sintéticos. Por exemplo, tudo que muda tem uma causa. Como estes juízos se formam? (R 4634, Ak. XVII, 616)

Para Reich, o objetivo de "demonstrar proposições e seu contrário", mencionado na $\mathrm{R} 5037$, não se refere às teses e às antíteses das antinomias cosmológicas, como quer Erdmann. Os antecedentes da demonstração de pares de proposições contraditórias (diferentes dos quatro conflitos antinômicos) já estão presentes em Os Sonhos de um visionário e na carta a Moisés Mendelssohn, de 8 de abril de 1766, cujo objetivo não é fomentar o ceticismo, mas mostrar qual é a fonte das disputas infindáveis da metafísica. Já em 1766, Kant pratica o método cético como princípio heurístico em questões da metafísica em geral, o qual é indispensável para o estabelecimento do verdadeiro método da metafísica. O método cético é empregado inicialmente não para tratar da cosmologia, mas da psicologia racional (Reich 1958, p. XII).

Também "a ilusão do entendimento" não se refere à ilusão transcendental. Na Crítica da razão pura, a ilusão transcendental consiste em considerar a tendência natural do pensamento ao incondicionado como uma ampliação do conhecimento, em atribuir realidade objetiva às idéias da razão (alma, mundo e Deus), que só têm valor subjetivo. Ao incondicionado faltam as duas condições do conhecimento objetivo: as intuições sensíveis e as categorias. A ilusão transcendental consiste em tratar essas três idéias como se fossem objetos do conhecimento, isto é, em tomar essas idéias, que são normas para a conduta do entendimento na organização da experiência, por representações de objetos efetivamente existentes. Mas Kant não concebe do mesmo modo a totalidade ou o incondicionado em $1770 \mathrm{e}$ 1781 e não distingue ainda, na Dissertação, categorias e idéias. As categorias, em 1770, referem-se às coisas em si (como os predicados mais gerais do ser), não sendo ainda a forma do pensamento de uma experiência possível e de seus objetos. A Dissertação apresenta Kant submetido profundamente em seu sonho dogmático, pois afirma a possibilidade de um conhecimento puramente intelectual dos objetos da metafísica.

Assim, ao negar a interpretação de Erdmann, Klaus Reich apresenta a seguinte tese: o espaço concebido como realidade absoluta ou como fenômeno de relação entre as substâncias deixou o problema da relação entre a alma e o corpo sem solução. Apesar de concordar com a interpretação geral de Reich, não posso aceitar a sua conclusão, que o problema do comércio psicofísico é o elemento determinante na gênese da Dissertação. Nesta obra a atenção de Kant está voltada para a cosmologia e não para a psicologia racional. 
Kant não concebe, em 1770, a doutrina do conflito da razão consigo mesma. Esta doutrina não pôde influenciar a Dissertação no que se refere à origem da idealidade e subjetividade do espaço e do tempo. Ao contrário, essa obra expõe e distingue as formas e os princípios do conhecimento do mundo sensível e do mundo inteligível. Não há dúvida que em 1770 Kant se ocupa com dois dos aspectos centrais da cosmologia (o mundo como totalidade de substâncias e as substâncias como partes do mundo), que com muitas alterações irão se constituir nas antinomias matemáticas, mas o tratamento que ele dá à sua cosmologia é ainda racional. Não obstante a sua nova doutrina do espaço e do tempo, Kant está nesse momento muito mais próximo de Leibniz e dos seus próprios textos da década de 1750 do que da Crítica da razão pura. As passagens da Dissertação que se referem ao tema cosmológico nada dizem sobre o conflito da razão consigo mesma.

De todos os elementos acima analisados a que a R 5037 faz referência, somente a doutrina da idealidade e subjetividade do espaço e do tempo e a ilusão estão presentes na Dissertação. Mas, apesar de o conceito de ilusão ter um papel fundamental no pensamento kantiano, ele não antecipa ainda o conceito de ilusão transcendental elaborado no início da dialética transcendental na Crítica da razão pura.

Argumento neste artigo que a descoberta do problema das antinomias só se tornou possível na medida em que Kant retomou, a partir de 1772, a consciência do problema da significação de conceitos e juízos, estabelecendo o domínio legítimo de sua aplicabilidade. ${ }^{4}$ Tal consciência possibilitou a distinção da lógica transcendental em analítica e dialética, isto é, uma lógica da verdade e uma lógica da ilusão. Em outras palavras, Kant só foi capaz de formular o problema das antinomias na segunda metade da década de 1770, após elaborar entre 1772 e 1775, ainda que na forma de um esboço, a idéia da analítica transcendental concebida como uma semântica transcendental.

Este artigo está dividido em quatro seções. Na primeira, ao tratar da distinção da lógica transcendental em analítica e dialética, analiso o projeto da dialética transcendental, elaborado em 1774-5 no Duisburg Nachlass, e ampliado na segunda metade da década de 1770. Neste período, Kant confere para a razão um uso teórico e um uso prático, buscando um princípio de unidade entre eles. Embora fundamental para a compreensão da dialética transcendental, o uso prático da razão não será objeto da minha atenção,

4 Daniel Omar Perez, ao questionar a distinção entre os períodos pré-crítico e crítico, defende que, nos textos anteriores a 1770, Kant discute principalmente problemas semânticos e não metafísiCos (Perez 2000, p. 151). Mas é curioso notar que na Dissertação, de 1770, as questões da semântica a priori estão ausentes. 
pois ultrapassa os objetivos dessa investigação. Na segunda seção examino a reformulação da problemática cosmológica da Dissertação, na segunda metade da década de 1770. Na terceira, investigo o papel do uso regulativo da razão, entre 1775 e 1777. Na quarta, investigo a teoria da razão entre 1778 e 1780.

\section{A dialética transcendental}

Comparado com o estado adiantado de elaboração dos principais temas e problemas da analítica transcendental na primeira metade da década de 1770, o tratamento dado, em toda esta década, aos problemas da dialética transcendental é incipiente. Até 1775 já estão esboçadas as soluções das deduções objetiva e subjetiva. Kant, ao estabelecer a correspondência entre juízos e categorias de relação, esboça a idéia do fio condutor para a descoberta de todos os conceitos puros do entendimento, que lhe permite elaborar o projeto da dedução metafísica. Também já está presente a teoria do esquematismo, embora não esteja claramente distinta da dedução transcendental das categorias, pois princípios e categorias ainda se confundem.

Até 1775 a dialética transcendental recebeu um tratamento secundário, visto que nesse período Kant estava ocupado em solucionar o problema da objetividade das representações intelectuais, elaborado na carta a Herz de 1772. Na R 4633, também de 1772, após discutir a possibilidade do conhecimento a priori dos objetos empíricos e matemáticos, Kant afirma, mas sem demonstrar, que a tentativa de aplicar conceitos puros além dos seus domínios legítimos, a saber, sem referência às intuições puras ou empíricas lança a razão em contradições inevitáveis: "Mas há outras, que querendo ter também uma origem a priori, se encontram lançadas sem cessar em contradições" (R 4633, Ak. XVII, 616). Embora não se trate ainda de demonstrar a impossibilidade da metafísica especial e, em particular, da cosmologia racional, Kant argumenta que conceitos e juízos sem referência às intuições puras ou empíricas são vazios.

Na R 4673, redigida no verso de uma carta de D. F. Lossow, datada de 28 de abril de 1774, Kant apresenta um exemplo de juízo ilegítimo. "Se um sujeito é uma coisa em geral e o predicado é o espaço e o tempo ou um conceito construído como sua condição, então o juízo é transcendente. (...) Eu não digo que seja falso, mas somente que não é concludente" (R 4763, Ak. XVII, 637-8). Um juízo transcendente é impossível (um juízo que não é concludente, nessa Reflexão, corresponde a um juízo impossível na Crítica da razão pura) na medida em que não é passível de ser verdadeiro ou falso. De acordo com a teoria da verdade transcendental, que está em processo de elaboração neste momento, um juízo possível deve satisfazer as condições 
intuitivas e conceituais. Neste sentido, Loparic ao comentar a Crítica da razão pura, escreve:

Um juízo sintético consistente é possível, ou seja, é capaz de ser verdadeiro ou falso - e, por conseguinte, justificado ou refutado, pelo menos em princípio - se duas condições semânticas forem preenchidas. Em primeiro lugar, o juízo deve conter, além de termos lógicos, somente conceitos objetivamente válidos. Em segundo lugar, deve ser possível interpretar sua forma discursiva por formas intuitivas dáveis na intuição sensível, pura ou empírica. (Loparic 2000, p. 203)

O Duisburg Nachlass, redigido em 1774-5, concebe, pela primeira vez, o entendimento e a razão como duas faculdades independentes ao distinguir, no conhecimento dos fenômenos, a matéria e a forma. A matéria é dada pela sensação. A forma é dada pela intuição pura espaço-temporal e pelo conceito. "O poder do pensamento é o entendimento (o poder do pensamento a priori, sem que o objeto seja dado, é a razão)" (R 4675 Ak, XVII, 651).

Tendo distinguido a razão do entendimento, Kant estabelece o plano geral da lógica transcendental, dividindo-a em analítica e dialética. Referindo-se à analítica transcendental, escreve: "A lógica transcendental trata dos conhecimentos do entendimento segundo seu conteúdo, mas de modo indeterminado quanto ao modo pelo qual os objetos são dados" (R 4675, Ak. XVII, 651). Por outro lado, "as regras universais ou princípios do pensamento em geral sem objetos determinados ou determinação do conhecimento a partir das relações aos objetos são sempre dialéticos" (R 4676, Ak. XVII, 656-7). A segunda parte da lógica transcendental investiga o uso dos conceitos puros além dos limites da experiência possível. Kant a denomina dialética, porque este uso é ilegítimo, uma vez que a um conceito dado pela razão não há na sensibilidade objeto que lhe corresponda. Esses "princípios do pensamento em geral" são, sem dúvida, os sintéticos a priori. Nessa Reflexão, Kant introduz o termo dialética ao distinguir entre tética e antitética transcendentais. A primeira tem por objeto "a construção dos princípios da razão pura"; a segunda, "o uso (natural) desses princípios em geral" (R 4676, Ak. XVII, 656), isto é, além do domínio da experiência possível. Esse uso natural é o uso dialético da razão, como comprova a R 4762, redigida entre 1775 e 1777: "Há um uso natural da nossa razão pura, mas esse uso é dialético" (R 4762, Ak. XVII, 718). Embora Kant empregue a palavra antitética, não concebe ainda o projeto da antitética transcendental, cuja tarefa é investigar as causas e as conseqüências da antinomia da razão pura. Constata apenas que o uso transcendente das categorias, embora natural, é ilusório, mas não atesta, como fará na Crítica da razão pura, que

(...) quando não nos limitamos a aplicar a nossa razão, no uso dos princípios do entendimento, aos objetos da experiência, mas ousamos alargar esses princípios para além dos limites desta experiência, surgem teses sofísticas, que da experiência não têm a 
esperar confirmação, nem refutação a temer, e cada uma delas não somente não encerra contradição consigo própria, mas encontra mesmo na natureza da razão condições da sua necessidade; a proposição contrária, porém, infelizmente, tem por seu lado fundamentos de afirmação igualmente válidos e necessários. (A 421; B 448-9)

Até 1775, a atenção de Kant está voltada para demonstrar a impossibilidade da ontologia. Neste sentido, ao atribuir à analítica transcendental a tarefa de apresentar as regras para a exposição dos fenômenos, encontramos apenas a antecipação da seguinte tese crítica:

O orgulhoso nome de ontologia, que se arroga a pretensão de oferecer, em doutrina sistemática, conhecimentos sintéticos a priori das coisas em si (por ex. o princípio da causalidade) tem de ser substituído pela mais modesta denominação de simples analítica dos conceitos. (A 247; B 303)

Na segunda metade da década de 1770, Kant amplia o projeto da lógica transcendental, elaborado inicialmente no Duisburg Nachlass. Tendo esboçado a analítica transcendental entre 1772 e 1775, sua atenção se volta agora para a dialética transcendental. Até 1775 atribuía à dialética transcendental um papel negativo, ou seja, o de demonstrar que o uso transcendente das categorias, embora natural, é ilusório. Tratava-se apenas de provar a impossibilidade da ontologia. Entre 1776 e 1778, embora Kant não distinga ainda categorias e idéias, e não faça a crítica à metafísica especial, concebe para a razão um uso regulativo (de ordenar os conhecimentos do entendimento), na esfera teórica, e um uso prático. Além disso, busca o acordo entre a razão teórica e a razão prática. Entre 1778 e 1780, ao criticar a metafísica especial, divide a dialética transcendental em paralogismos, antinomia e ideal da razão pura, mas não se detém em analisá-los.

Comecemos com as Reflexões que atribuem um papel negativo à dialética transcendental: "A primeira parte da filosofia transcendental é aquela que assenta sobre o conhecimento imanente a priori: a analítica; - a segunda assenta sobre o conhecimento transcendente: a dialética. Ambas são partes da crítica" (R 5127, Ak. XVIII, 99-100). "A dialética transcendental é a crítica da ilusão e a analítica é a doutrina da verdade. Nos antigos ela era principalmente uma técnica da ilusão ou uma arte sofística. A crítica da ilusão vem depois da filosofia" (R 5063, Ak. XVIII, 76). Kant denomina a dialética transcendental uma lógica da ilusão, cuja tarefa é destituir a razão de suas pretensões de estender o conhecimento além dos limites da experiência possível. A ilusão transcendental consiste em considerar a tendência natural do pensamento ao supra-sensível uma ampliação do conhecimento. Na R 5058, Kant, ao tratar da ilusão transcendental em termos de juízo, sem relacioná-la com o incondicionado, esclarece que ela surge ao confundirmos a necessidade subjetiva de ordenarmos, a partir dos princípios da ra- 
zão, os conhecimentos do entendimento pela necessidade objetiva relativa à constituição das próprias coisas:

A ilusão, em todos os juízos, depende da confusão do subjetivo com o objetivo. Principalmente nos princípios da razão, onde os princípios subjetivos a priori podem ser objetivos.

Na ciência transcendental tudo deve ser tirado do sujeito, mas apenas na medida em que é referido aos objetos; por isso a dialética é algo que pertence à natureza do entendimento e possibilita uma ciência. (R 5058, Ak. XVIII, 75)

Se no domínio da razão especulativa nos é vedado o acesso ao suprasensível, o mesmo não ocorre com a razão prática. Seria um reducionismo atribuir à dialética transcendental apenas o caráter negativo, pois esta descrição não permite compreender adequadamente o seu papel na estrutura da lógica transcendental, dado que se se tratasse unicamente de estabelecer o caráter ilegítimo da pretensão da razão teórica de conhecer a coisa em si, a dialética transcendental seria inútil. Os esboços da estética e da analítica transcendentais, que a precedem, demonstraram que a coisa em si não pode ser conhecida. Assim, a dialética transcendental não pode ser compreendida apenas em oposição à analítica transcendental, como sugere a $\mathrm{R}$ 5063. Na R 4849, redigida entre 1776 e 1778, Kant concebe a metafísica como a filosofia transcendental, ${ }^{5}$ detalhando o projeto a ser realizado pela lógica transcendental:

A metafísica tem por finalidade: 1. descobrir a origem do conhecimento sintético a priori; 2. compreender as condições restritivas do uso empírico da nossa razão; 3. mostrar a independência da nossa razão dessas condições, portanto a possibilidade de seu uso absoluto; 4. assim, estender nosso uso da razão além dos limites do mundo sensível, mesmo que seja de maneira negativa, isto é, retirar o obstáculo que a própria razão constitui a partir dos princípios de seu uso empírico; 5. mostrar a condição de sua unidade absoluta para que ela possa ser um princípio completo de unidade prática, isto é, do acordo de todos os fins em um todo. (Estes mesmos princípios de extensão são, por sua vez, negativos em relação ao uso empírico, no qual nada, apenas a natureza é válida.)

O uso dogmático de nossa razão não pode ser objetivamente determinado, além dos limites da experiência (possível), e não há síntese nova; trata-se apenas de um acordo entre unidade teórica e unidade prática. (...)

(A libertação da unidade da razão das restrições de seu uso empírico torna possível seu uso transcendental).

Visto que a extensão da razão aqui é apenas negativa, não obstante a unidade absoluta do conhecimento de objetos em geral e de todos os seus fins (livre de todas

5 Na R 4849, Kant amplia o conceito de filosofia transcendental também para a razão prática. Nas Reflexões da primeira metade da década de 1770 limitava-o à razão teórica. 
as restrições da sensibilidade) é requerida pela espontaneidade absoluta da razão, sendo assim a extensão é praticamente necessária.

A razão é o poder da unidade absoluta de nosso conhecimento. (R 4849, Ak. XVIII, 5-6)

Kant apresenta as tarefas que devem ser realizadas pela investigação metafísica. A primeira explica a origem dos elementos dos juízos sintéticos a priori. Embora as expressões exposição metafísica e dedução metafísica estejam ausentes, Kant demonstra que o espaço, o tempo e as categorias são representações a priori. A segunda tarefa, denominada exposição dos fenômenos (expressão que corresponde à dedução transcendental das categorias na Crítica da razão pura), consiste em provar que a validade objetiva das categorias está limitada à experiência e seus objetos. Essas duas tarefas já foram realizadas na primeira metade da década de 1770. A novidade dessa Reflexão é referente ao uso prático da razão e consiste na terceira tarefa da metafísica. Somente no domínio da moralidade a razão pura tem uma função positiva. Finalmente, ao estabelecer para a metafísica a tarefa de propiciar o princípio de unidade (não apresentado nessa Reflexão) entre a razão teórica, que visa à unidade absoluta do conhecimento de objetos da experiência possível, e a razão prática, relativa aos fins das ações humanas, Kant antecipa a seguinte formulação crítica:

Eis por que uma crítica que limita a razão especulativa é, como tal, negativa, mas na medida em que anula um obstáculo que restringe ou mesmo ameaça aniquilar o uso prático da razão, é de fato de uma utilidade positiva e altamente importante, logo que nos persuadirmos de que há um uso prático absolutamente necessário da razão pura (o uso moral), no qual esta inevitavelmente se estende para além dos limites da sensibilidade, não carecendo para tal, aliás, de qualquer ajuda da razão especulativa, mas tendo de assegurar-se contra a reação desta, para não entrar em contradição consigo mesma. (B XXV)

A tendência natural da razão em ultrapassar o domínio da experiência possível tem também uma função positiva. Sem distinguir ainda regras e princípios, Kant atribui à razão teórica a função positiva de unificar os conhecimentos do entendimento. Enquanto o entendimento unifica as aparências mediante regras, a razão confere unidade ao entendimento (Kant não explica como esta operação é realizada), função denominada, na Crítica da razão pura, uso regulativo da razão. A ilusão metafísica surge apenas quando supomos que a razão pura pode conhecer seus objetos, independentemente da experiência.

\section{A gênese das antinomias}

Após distinguir a razão do entendimento, a lógica transcendental em analítica e dialética, atribuir à dialética o papel de crítica da ilusão trans- 
cendental, e conceber um uso regulativo e um uso prático para a razão, Kant tem os elementos para iniciar a elaboração das antinomias. Só depois de ter negado a intuição intelectual, ou melhor, ter demonstrado a impossibilidade do uso real do entendimento, na primeira metade da década de 1770, ele está em condições de reformular, entre 1775 e 1780, a problemática cosmológica elaborada na Dissertação de 1770. Nesta obra, ao conceber o fenômeno e a coisa em si como objetos da cosmologia, Kant defende que é possível conciliar a impossibilidade de determinar o último elemento da matéria e sua totalidade no mundo fenomênico com a simplicidade e a totalidade das substâncias no mundo numênico. Esta conciliação é possível, pois, ao separar ciência e metafísica, Kant concebe dois mundos distintos, cada um com matéria e forma próprias. No mundo sensível, a impossibilidade de completar a série dos fenômenos para constituir o mundo como totalidade antecipa a antítese da primeira antinomia e a impossibilidade de chegar à parte última da matéria, a antítese da segunda antinomia. Mas no mundo inteligível, a busca pela totalidade e pelo simples não antecipa, respectivamente, as teses da primeira e segunda antinomias, pois a totalidade e o simples procurados na Crítica da razão pura são fenomênicos e estão fundados sobre as leis da intuição sensível, enquanto na Dissertação são substâncias e a forma de sua relação é estabelecida por Deus. Enquanto em 1770, por estar ausente o conflito da razão consigo mesma, as proposições sobre o todo e o simples na esfera da intuição sensível e na esfera da intuição intelectual são verdadeiras, em 1781-7 as teses e as antíteses das antinomias matemáticas, por não serem proposições possíveis, constituem-se num falso problema da razão pura e são eliminadas do programa da filosofia transcendental. As proposições são possíveis apenas na medida em que se referem às intuições puras ou empíricas. As teses e as antíteses das antinomias matemáticas não são proposições possíveis, porque os conceitos de mundo, infinito e simples nelas empregados são vazios, uma vez que não têm objetos aos quais se referir.

Nas questões referentes à cosmologia, a razão se envolve em contradições que a obrigam a desistir de suas pretensões de ampliação do conhecimento. A antinomia da razão pura ao apresentar quatro problemas sobre o mundo e admitir para cada um soluções contrárias e demonstráveis com todo o rigor na perspectiva do realismo transcendental leva as questões cosmológicas a um impasse. Neste sentido é impossível uma solução dogmática de cada conflito, pois a análise dos argumentos de cada um dos lados em disputa não nos permite decidir qual das partes tem validade objetiva. Visto que a razão pura tem a tendência natural para ultrapassar os limites da experiência possível e tomar o incondicionado como objeto de conhecimento, Kant formula, na introdução da Crítica da razão pura, a tese da decidibilidade dos problemas da razão pura: 
Tem que ser possível, no que se lhe refere, atingir uma certeza: a do conhecimento ou ignorância dos objetos, isto é, uma decisão quanto aos objetos das suas interrogações ou quanto à capacidade ou incapacidade da razão para formular juízos que se lhes reportem; conseqüentemente, para estender com confiança a nossa razão ou para lhe pôr limites seguros e determinados. (B 22)

O que permite a Kant decidir que a metafísica tradicional é impossível como ciência é a demonstração de que os conceitos e juízos com os quais ela opera são vazios, pois os limites do conhecimento humano se identificam com conceitos e proposições possíveis. O método cético visa a resolver um caso particular da metafísica: o referente à antinomia da razão pura:

Este método de assistir a um conflito de afirmações, ou antes, de o provocar, não para se pronunciar no fim a favor de uma ou outra parte, mas para investigar se o objeto da disputa não será mera ilusão, que qualquer delas persegue e com a qual nada ganharia, mesmo se não encontrasse resistência, tal modo de proceder, digo, é o que se pode chamar método cético. (A 423-4; B 451)

As duas primeiras antinomias surgem da ilusão natural e inevitável que é produzida pela exigência da razão em completar a série absoluta das condições dos fenômenos como totalidade e partes simples. A razão gera os problemas das antinomias matemáticas ao buscar o incondicionado. A sensibilidade nos dá apenas um múltiplo de representações sensíveis (pura ou empírica). O entendimento, através dos seus conceitos puros, estabelece uma conexão necessária entre essas representações e constitui o objeto matemático ou empírico. A razão pretende levar o conhecimento produzido pelo entendimento a uma unidade suprema. O conhecimento produzido pela sensibilidade e entendimento é condicionado, pois depende de nosso aparato cognitivo, mas a unidade suprema pretendida pela razão é incondicionada. Por meio do incondicionado, o entendimento alcança a coerência geral consigo mesmo. Embora a busca do incondicionado faça parte do interesse natural da razão teórica, o progresso no conhecimento do condicionado ao incondicionado não implica uma necessidade objetiva, mas subjetiva:

A diversidade das regras e a unidade dos princípios é uma exigência da razão para levar o entendimento ao mais completo acordo consigo próprio. (...) Mas um tal princípio não prescreve aos objetos nenhuma lei e não contém o fundamento da possibilidade de os conhecer e de os determinar como tais em geral; é simplesmente, pelo contrário, uma lei subjetiva da economia no uso das riquezas do nosso entendimento. (A 305-6; B 362)

$\mathrm{Na}$ busca do incondicionado, a razão opera com as categorias sem referi-las aos objetos dos sentidos, fazendo destes conceitos um uso transcendente e, portanto, abusivo. A razão pode pensar o incondicionado, mas não 
pode conhecê-lo. O incondicionado, ou como Kant também o denomina, as idéias transcendentais, refere-se a algo que abrange todas as experiências, mas nunca é objeto da experiência (A 310; B 367). Enquanto o entendimento transforma a multiplicidade indeterminada de representações sensíveis num conhecimento objetivo, a razão leva a unidade produzida pelo entendimento a uma unidade superior. Assim, "todo o nosso conhecimento começa pelos sentidos, daí passa ao entendimento e termina na razão, acima da qual nada se encontra em nós mais elevado que elabore a matéria da intuição e a traga à mais alta unidade do pensamento" (A 298-9; B 355). Na busca da unidade suprema, a razão não se depara apenas com uma idéia transcendental, mas com três: o incondicionado como unidade absoluta do sujeito pensante, que é o objeto da psicologia racional; o incondicionado como totalidade dos fenômenos e suas condições no espaço e no tempo, que é o objeto da cosmologia racional, e o incondicionado como unidade absoluta da condição de todos os objetos do pensamento, que é o objeto da teologia racional.

Os paralogismos, a antinomia e o ideal da razão pura estão baseados em argumentos dialéticos, e o objetivo de Kant é demonstrar que todos os conhecimentos referentes à psicologia, à cosmologia e à teologia racionais são ilusões, não empíricas, como as ilusões óticas, mas transcendentais. Por isso, a dialética transcendental é precedida por um significativo capítulo introdutório dividido em duas seções: a primeira é denominada "da aparência transcendental", e a segunda, "da razão pura como sede da aparência transcendental". Ao preceder a dialética com a análise da ilusão transcendental, Kant pretende dar a esta segunda parte da sua lógica uma orientação precisa, isto é, mostrar que a verdade ou a ilusão estão no juízo na medida em que, através dele, pensamos os objetos.

A verdade ou a ilusão não estão no objeto, na medida em que é intuído, mas no juízo sobre ele, na medida em que é pensado. Pode-se, pois, dizer que os sentidos não erram, não porque o seu juízo seja sempre certo, mas porque não ajuízam de modo algum. Eis por que só no juízo, ou seja, na relação do objeto com o nosso entendimento, se encontram tanto a verdade como o erro e, portanto, também a aparência, enquanto induz a este último. (A 293; B 350)

Na Lógica, editada por Jäsche, Kant afirma: "O contrário da verdade é a falsidade, a qual, na medida em que é tomada pela verdade, se chama erro. Por conseguinte, um juízo errôneo - pois o erro assim como a verdade só existe no juízo - é um juízo que confunde a aparência da verdade com a própria verdade" (Kant 1800, Ak 76). Esta indicação já foi estabelecida no início da lógica transcendental, visto que é somente em relação ao problema da verdade do conhecimento que é discutida a possibilidade de um uso ilegí- 
timo dos princípios lógicos e que surge a possibilidade da ilusão. Na dialética transcendental, os três grandes problemas da metafísica especial (a alma, o mundo e Deus) são situados no campo da aparência transcendental, e Kant, ao definir este conceito, distingue-o da aparência empírica e da aparência lógica, mostrando que enquanto a última pode ser facilmente dissipada, em contrapartida, a aparência transcendental, por tratar-se de uma ilusão natural e inevitável,

(...) não cessa, ainda mesmo depois de descoberta e claramente reconhecida a sua nulidade pela crítica transcendental (por exemplo, a aparência na proposição seguinte: O mundo tem de ter um começo no tempo). (...) Ilusão esta que é inevitável, assim como não podemos evitar que o mar nos pareça mais alto ao longe do que junto à costa, porque, no primeiro caso, o vemos por meio de raios mais elevados; ou ainda, como o próprio astrônomo não pode evitar que a lua, ao nascer, lhe pareça maior, embora não se deixe enganar por essa aparência. (A 297; B 353-4)

\section{A aparente antinomia da razão pura}

O tratamento dado à dialética transcendental, na segunda metade da década de 1770, pode ser dividido em dois momentos. No primeiro, que é objeto de investigação da presente seção, estão contidas as Reflexões 4756 a 4760, datadas entre 1775 e 1777. Entre elas e a Crítica da razão pura há diferenças fundamentais. Nessas Reflexões está ausente a tripartição da dialética transcendental em paralogismos, antinomia e ideal da razão pura.

No segundo momento, compreendido entre 1778 e 1780, objeto de investigação da próxima seção, Kant distingue as categorias das idéias, atribuindo à dialética transcendental a tarefa de demonstrar a impossibilidade da metafísica especial. Nas Reflexões 5552 a 5555, ao elaborar o conceito de idéia transcendental e estabelecer o caráter inferencial da faculdade da razão, Kant estabelece o inventário dos problemas necessários da razão: a idéia da unidade absoluta do sujeito pensante, objeto da psicologia racional; a idéia da unidade absoluta da série das condições do fenômeno, objeto da cosmologia racional; e a idéia da unidade absoluta da condição de todos os objetos do pensamento em geral, objeto da teologia racional. Mas a análise de cada um desses ramos da metafísica especial é objeto da atenção de Kant apenas nas Reflexões do período de redação da Crítica da razão pura.

Embora nas Reflexões redigidas entre 1775 e 1777 Kant negue a cosmologia da Dissertação de 1770 e empregue as expressões "dialética da sensibilidade", "dialética do entendimento" (R 4756, Ak. XVII, 699-700) e "regras dialéticas" (R 4757, Ak. XVII, 704), constata, nesse momento, apenas uma "aparente antinomia da razão pura" (R 4757, Ak. XVII, 704). Estando ausente o conflito da razão consigo mesma, ele não tem consciência ainda que a 
antinomia da razão pura só existe na perspectiva do realismo transcendental e sua solução só pode ser dada pelo idealismo transcendental. Kant atribui à razão teórica uma função reguladora, cujo papel é introduzir completude e sistematicidade ao conhecimento elaborado pelo entendimento. Mas não negligencia o aspecto prático da razão e afirma que a unidade da razão deve ser compreendida como teórica e prática.

$\mathrm{Na}$ R 4757 Kant distingue os princípios imanentes do uso empírico do entendimento (que são princípios da possibilidade da experiência e dos seus objetos) dos princípios transcendentes do uso puro da razão ${ }^{6}$ (cujo papel é introduzir completude e sistematicidade ao conhecimento elaborado pelo entendimento). Mas não conclui ainda que os princípios transcendentes do uso puro da razão, na medida em que buscam o incondicionado para o conhecimento condicionado do entendimento, são as fontes da ilusão transcendental:

Os princípios da possibilidade da experiência (da unidade distributiva) são ao mesmo tempo princípios da possibilidade dos objetos da experiência: 1. (unidade) da intuição (fenômeno); 2. de serem dados os fenômenos ou sua existência.

Princípios imanentes (espaço e tempo são condições do fenômeno) ou transcendentes (não são).

Os princípios do uso empírico do entendimento são imanentes. Os princípios do uso puro da razão são transcendentes. O acordo da razão consigo mesma num todo.

Os primeiros não precisam de um primeiro termo a priori, senão a posteriori e se faz a progressão ou regressão ao infinito.

Princípios imanentes do uso empírico do entendimento [empirischen Verstandesgebrauch]:

1. Não há limite da composição e decomposição dos fenômenos.

2. Não há causa primeira ou primeiro começo.

3. Tudo é mutável e variável, portanto empiricamente contingente, porque o tempo é em si necessário, mas nada está necessariamente fixado ao tempo.

Princípios transcendentes do uso puro do entendimento [reinen Verstandesgebrauch]:

1. Há uma primeira parte, a saber, o simples como princípio da composição. E há limites para todos os fenômenos juntos.

2. Há uma liberdade absoluta, uma liberdade transcendental.

3. Há algo de necessário em si, a saber, a unidade da realidade suprema, em que toda variedade de possibilidades pode ser determinada através de limites. Visto que o espaço e o tempo são apenas condições dos fenômenos, deve haver um princípio da unidade da razão pura, pelo qual o conhecimento possa ser determinado sem relação aos fenômenos. (R 4757, Ak. XVII, 703-4)

6 Embora Kant faça, na R 4757, a distinção entre os princípios do uso empírico do entendimento e os princípios do uso puro da razão, não segue uma terminologia fixa. Nessa Reflexão, os princípios do uso puro da razão são denominados de princípios transcendentes do uso puro do entendimento. 
Nos três princípios imanentes do uso empírico do entendimento e nos três princípios transcendentes do uso puro do entendimento (princípios transcendentes do uso puro da razão), Kant antecipa a formulação dos quatro pares de proposições que, após 1780, constituirão as antinomias. ${ }^{7}$ Os primeiros princípios antecipam as antíteses e os últimos antecipam as teses. No domínio do conhecimento empírico não há limites para a composição e decomposição dos fenômenos, pois o todo e o simples não são objetos da intuição sensível; não há causalidade pela liberdade, apenas determinismo segundo as leis da natureza; não há, também, um ser absolutamente necessário como condição dos fenômenos. Por outro lado, há limites determinados para a composição e decomposição dos fenômenos no domínio da razão pura, há uma causalidade pela liberdade e há, também, uma existência absolutamente necessária como condição dos fenômenos.

Embora os primeiros princípios antecipem as antíteses, e os últimos as teses das antinomias cosmológicas, Kant não conclui ainda que este conjun-

7 Embora a R 4757 já antecipe os quatro pares de proposições da antinomia da razão pura, não formula separadamente os princípios imanentes do uso empírico do entendimento referente ao todo e ao simples. Também não formula separadamente os princípios transcendentes do uso puro do entendimento.

A R 4759 apresenta separada e esquematicamente os quatro pares de proposições, que após 1780 constituirão as antinomias.

(Exposição e (compreensão) racionalidade.)

(Aos fenômenos.) (Unidade da experiência e unidade da razão.)

Os princípios da exposição dos fenômenos pressupõem que eles são condicionados, pois não são colocados absolutamente:

1. Nenhuma totalidade absoluta (da síntese) da composição, pois a progressão é infinita. (...)

2. Nenhuma totalidade absoluta [divisão] da decomposição, pois nenhum simples incondicional. (...)

(O progresso infinito não pode ser concebido e o incondicionado não pode ser intuído.)

3. Nenhuma totalidade absoluta da série da produção. Nenhuma espontaneidade incondicional.

4. Nenhuma necessidade incondicional. Todas as coisas podem ser tomadas no tempo e no espaço.

(O mundo em sentido físico

Simples -

Necessidade

Espontaneidade ----------.)

Todas essas proposições são (objetivamente) certas como fundamento do uso empírico, mas contrárias à razão.

(Das coisas em geral)

Princípios da racionalidade ou da compreensão. Do universal ao particular: síntese absoluta.

1. Totalidade incondicionada do todo. Origem do mundo.

2. Simples incondicionado.

3. Espontaneidade incondicionada da ação.

4. Existência necessária incondicionalmente.

Essas proposições são subjetivamente necessárias como princípios do uso da razão no todo do conhecimento: unidade da totalidade do diverso do conhecimento do entendimento" (R 4759, Ak. XVII, 709-10) 
to de proposições opostas são o produto de inferências igualmente válidas realizadas pela razão. Estando ausente o conflito da razão consigo mesma, não há contradição entre os princípios imanentes do uso empírico do entendimento e os princípios transcendentes do uso puro da razão, pois sendo de faculdades diferentes, há apenas uma aparente antinomia da razão pura, que, não sendo necessária e natural, pode ser evitada ao serem respeitadas certas regras referentes ao uso das faculdades de conhecimento:

\section{Causa da antitética ou da aparente antinomia da razão pura.}

Aqueles são princípios da exposição dos fenômenos [Exposition der Erscheinungen], esses da espontaneidade da razão pura [Spontaneität der reinen Vernunft]. O acordo completo da razão consigo mesma, portanto também da moralidade.

Nós devemos ter princípios da unidade original ou da unidade sistemática de nossos conhecimentos, isto é, da sua espontaneidade, na medida em que nós agimos independente e queremos determinar praticamente os fenômenos ou nós mesmos entre os fenômenos de modo original.

Eles são princípios da autodeterminação da razão.

Ou da unidade do todo das nossas determinações da razão.

Todos os conhecimentos possíveis constituem um todo para a razão, pois a síntese da unidade absoluta é a condição da razão. (R 4757, Ak. XVII, 704)

A razão, ao buscar o incondicionado através de seus princípios transcendentes, introduz completude e sistematicidade ao conhecimento condicionado pela sensibilidade e pelo entendimento. $\mathrm{O}$ incondicionado faz parte do interesse natural da razão teórica, mas o progresso no conhecimento do condicionado ao incondicionado implica uma necessidade subjetiva. Embora Kant não tenha formulado ainda o conceito de idéia transcendental, esboça a distinção dos princípios da razão em regulador e constitutivo. Sem explicação, afirma que a razão pura, ao conceber o simples e o todo como incondicionados, introduz apenas coerência e unidade ao entendimento. A ilusão transcendental, que dá origem às antinomias da razão pura, surge apenas quando confundimos os princípios reguladores com os constitutivos.

Ora, se o todo e o simples no domínio da razão teórica têm a função reguladora de trazer unidade e sistematicidade ao conhecimento do entendimento, é apenas como razão prática que a razão pura tem uma função construtiva. Só neste domínio a razão pode ultrapassar os limites da experiência possível e alcançar o incondicionado. ${ }^{8}$

8 As reflexões redigidas na segunda metade da década de 1770 comprovam que Kant se ocupou também com a filosofia prática. Apesar de interessantes para a compreensão da gênese da filosofia crítica como um todo, os esboços da filosofia prática não serão estudados nesse trabalho, pois meu interesse está limitado à razão teórica. Apenas para ilustrar, cito duas Reflexões cuja análise pressupõe uma interpretação geral da filosofia moral de Kant, que não será dada aqui. 
No fim da R 4757, Kant apresenta as regras para evitar a aparente antinomia da razão pura:

Dialéticas.

Regras.

1. O que não pertence aos fenômenos, não pode ser julgado segundo as regras dos fenômenos. Isto é, Deus com o espaço e o tempo.

2. Não submeter às suas condições o que não pertence ao fenômeno externo, por exemplo, o espírito.

3. O que não pode ser concebido (e o que não pode ser representado na intuição) não devem ser tomados como impossíveis: a totalidade do infinito ou a divisão infinita. A infinitude da série, a finitude do ser derivado sem substrato original.

Não confundir os princípios da unidade absoluta da razão com aqueles da unidade empírica.

a. Simplicidade do sujeito pensante.

b. Liberdade como condição das ações racionais.

c. O ser originário como substrato de toda ligação de suas representações em um todo.

d. Não confundir a restrição do mundo relativa à origem e conteúdo com limitação.

Os princípios da razão são as condições (determinação) da unidade de nosso conhecimento, na medida em que ele é determinável a priori, por conseqüência, somente aquele que contém a integridade do conhecimento especulativo a priori, que concorda com as idéias do conhecimento prático a priori. (R 4757, Ak. XVII, 704)

A solução metodológica apresentada aqui difere da estabelecida em 1770. A Dissertação separa as ciências intuitivas (física e matemática) da metafísica, concebendo dois objetos distintos de conhecimento: o fenômeno e a coisa em si. A possibilidade da metafísica é assegurada ao atribuir ao entendimento um uso real e ao ser respeitado o seguinte princípio metodológico: "os princípios próprios do conhecimento sensitivo não podem ul-

\footnotetext{
Apesar de negligenciar a distinção entre razão e entendimento, estabelecida desde o Duisburg Nachlass, Kant escreve entre 1776 e 1778: "No mundo dos sentidos nós seguimos os princípios do conhecimento empírico, no mundo do entendimento, os princípios do conhecimento puro do entendimento. Os últimos não têm relação alguma com a exposição dos fenômenos (...), mas apenas com aquilo que é dado através do entendimento (uso puro da liberdade). Aqui a pressuposição necessária é que Deus existe. Uma crença" (R 4972, Ak. XVIII. 45).

Entre 1775 e 1778, Kant distingue a liberdade transcendental da liberdade prática. "A liberdade transcendental é a hipótese necessária de toda regra, portanto de todos os usos do entendimento. Nós devemos assim e assim pensar. Por conseguinte esta ação deve ser livre, isto é, não ser já determinada de si (subjetivamente), mas antes ter um fundamento objetivo de determinação. É a (condição da) qualidade dos seres para quem a consciência de uma regra é o fundamento de suas ações" (R 4904, Ak. XVIII, 24).

Sobre as concepções kantianas de razão teórica e prática e a unidade da razão pura, cf. Paul Guyer (1989).
} 
trapassar os seus limites e não podem chegar ao conhecimento intelectual" (Kant 1770, § 24).

Tendo demonstrado a impossibilidade do uso transcendente das categorias nas Reflexões da primeira metade da década de 1770, Kant inverte, entre 1775 e 1777, o princípio metodológico da Dissertação, recomendando "não confundir os princípios da unidade absoluta da razão com aqueles da unidade empírica" (R 4757, Ak. XVII, 704). Sendo assim, não se trata mais de evitar que o inteligível seja contaminado pelo sensível, mas de não atribuir realidade objetiva à atividade reguladora da razão, cuja função é apenas ordenar os conhecimentos do entendimento. Isto é, não se deve supor que aos conceitos da razão pura correspondam, de fato, objetos. A ilusão transcendental surge ao se transformar a unidade do conhecimento, sob o aspecto de idéia subjetivamente válida, em uma concepção ontológica do mundo. O simples e o todo, que são meras regras para a ordenação e sistematização do conhecimento empírico, não podem ser concebidos como objetos do conhecimento.

A aparente antinomia da razão pura se dissolve quando se constata que não se trata ainda da antecipação da tese crítica, segundo a qual a razão pura elabora pares de proposições opostas com a mesma pretensão de validade objetiva, mas de um mero conflito subjetivo entre as faculdades de conhecimento em suas relações com os fenômenos:

Conflito subjetivo entre o caráter parcial da sensibilidade e a totalidade da razão na determinação do conhecimento:

As condições do uso empírico na exposição dos fenômenos.

As condições do uso racional na compreensão dos fenômenos. (R 4759, Ak. XVII, 710)

Ao conhecimento condicionado pela sensibilidade e entendimento, Kant opõe o conhecimento incondicionado pela razão. Enquanto toda síntese empírica é condicionada, a síntese intelectual, atividade da razão, é incondicionada. A aparente antinomia da razão pura se dissolve se não atribuirmos validade objetiva aos princípios da unidade absoluta da razão, realizada pela síntese incondicionada e puramente intelectual:

O fundamento da antinomia da razão é o conflito: 1.Toda síntese empírica é condicionada, tanto a matemática quanto a dinâmica. A. Todo fenômeno tem partes e ele próprio é uma parte. B. Tudo o que acontece é um efeito (o que é, é condicionado) e ele mesmo é uma causa. Não há primeiro nem último termo. Nada simples, nenhum limite da grandeza, nenhuma causa primeira e nenhum ser necessário. Nesses pontos nós não podemos chegar com os fenômenos (e não devemos invocá-los em seu favor). Pelo contrário, 2. a síntese transc. (por meio dos conceitos puros da razão) é incondicionada, mas se dá por puros conceitos intelectuais; não há, de fato, antinomia. O mundo é limitado. Há o simples. Há liberdade. Há um ser necessário. Fun- 
damento desses princípios. Unidade total do uso da razão, através do qual ele tem unidade coletiva. (R 4760, Ak. XVII, 711)

Embora Kant utilize uma terminologia crítica (condicionado/incondicionado), ele não concebe o incondicionado no duplo sentido empregado na Crítica da razão pura. O conflito que Kant tem em mente não é ainda entre dois tipos de incondicionados, no qual o primeiro consiste na totalidade da série e o segundo, em uma parte da série:

Pode conceber-se este incondicionado de duas maneiras: ou como consistindo simplesmente na série total, sendo, portanto, condicionados todos os membros, sem exceção, e só a totalidade seja absolutamente incondicionada; neste caso diz-se que a regressão é infinita; ou então o incondicionado absoluto é apenas uma parte da série a que os restantes membros estão subordinados, mas não se encontrando ela própria submetida a nenhuma outra condição. No primeiro caso a série é a parte priori sem limites (sem começo), isto é, infinita e no entanto dada integralmente, embora a sua regressão nunca seja acabada e só possa chamar-se virtualmente infinita. No segundo caso há um primeiro termo da série que em relação ao tempo decorrido se chama início do mundo, em relação ao espaço, limite do mundo; simples, em relação às partes de um todo dado em seus limites; espontaneidade absoluta (liberdade); necessidade natural absoluta, em relação à existência de coisas mutáveis. (A 417-8; B 445-6)

\section{A razão}

Na primeira metade da década de 1770, Kant esboça os principais elementos da analítica transcendental e demonstra a impossibilidade da ontologia. Entre 1776 e 1778, atribui à razão teórica um uso regulativo e concebe o uso prático da razão, mas não empreende ainda a crítica à metafísica especial. Provavelmente, este era o último obstáculo que deveria ser removido para que o projeto crítico, elaborado inicialmente na carta a Herz de 1772, fosse efetivado. ${ }^{9}$ Desde 1772 , Kant apresenta, em algumas de suas cartas a Marcus Herz, a intenção de publicar a Crítica da razão pura, mas se depara a cada momento com um novo problema que o obriga a adiar novamente a publicação dessa obra. Em 24 de novembro de 1776, Kant escreve a Herz:

Eu recebo de todos os lados reprovação sobre a inatividade na qual eu pareço estar há um longo tempo, e eu não poderia ter sido mais sistemático nem mais contínuo em meu trabalho do que durante o período em que não nos vimos. Os materiais, pela exposição dos quais eu poderia esperar uma aprovação passageira, acu-

9 Na R 4849, Kant reformula e amplia o projeto crítico, no qual concebe a razão como teórica e prática. 
mulam-se em minhas mãos como acontece ordinariamente quando se é mestre em alguns princípios fecundos. Mas todos são retidos por um objeto principal, que se assemelha a um dique, do qual eu espero tirar um mérito durável, de posse do qual eu creio estar e sobre o que não há tanto mais a pensar do que expor. Após realizar este trabalho, que agora apenas menciono, (...) depois de remover os últimos obstáculos, eu libero um campo: trabalhar esse campo não será mais que uma diversão para mim. (Kant 1991, p. 138)

Na mesma carta, ao retomar o projeto crítico e mais uma vez ampliá-lo, Kant menciona o problema que o impede de executá-lo. O dique que ele pensa poder transpor em um curto período é constituído pelos raciocínios dialéticos da razão pura (denominados nessa carta de raciocínios sutis). Kant parece estar consciente de que a transposição desse obstáculo pressupõe a elaboração da teoria da razão:

Você sabe que o campo da razão que julga independentemente de todos os princípios empíricos, isto é, o campo da razão pura, deve ser dominado. (...) Para estabelecer agora em princípios seguros o relevo de toda a extensão desse campo, de suas divisões, de seus limites, de seu conteúdo e colocar de tal maneira a fronteira para se saber com certeza se se encontra sobre o terreno da razão ou dos raciocínios sutis, é necessário uma crítica, uma disciplina, um cânon e uma arquitetônica da razão pura. (Kant 1991, p. 138)

Na carta a Marcus Herz de 20 de outubro de 1777, na do início de abril de 1778 e nas Reflexões desse período, Kant não elabora ainda a teoria da razão, embora já tenha apresentado, desde 1774-5, alguns elementos da distinção entre entendimento e razão. É a teoria da razão que lhe permite relacionar o incondicionado com a ilusão transcendental, explicar como e por que são gerados os problemas da metafísica especial, quais são os problemas necessários da razão e quais os meios de resolvê-los. Ainda envolvido nas dificuldades de realização do seu projeto, isto é, nos problemas relacionados com a atividade da razão, Kant escreve, em 20 de outubro de 1777, a Marcus Herz:

Após a nossa separação, minhas pesquisas, outrora consagradas de um modo fragmentário aos mais diversos objetos da filosofia, têm tomado uma forma sistemática e me têm conduzido gradualmente à idéia do todo, que tem por primeiro efeito tornar possível o julgamento sobre o valor e a influência recíproca das partes. A conclusão de todos esses trabalhos, que eu nomeio Crítica da razão pura, encontra nesse momento um obstáculo, como se fosse uma pedra, que barra o caminho. Eu me empenho exclusivamente, nesse momento, em tirá-lo e espero concluí-la nesse inverno. (Kant 1991, p.145)

Novamente em 1778, Kant menciona as dificuldades para concluir a sua obra: 
Algumas folhas, do trabalho que eu tenho em minhas mãos, estão prontas para impressão. (...) Esse trabalho se expande e eu espero terminá-lo. Eu espero que você compreenda um dia a natureza da dificuldade e do projeto, e os motivos que levaram ao atraso do escrito. (Kant 1991, p. 158-59)

Na carta a Herz, de 24 de novembro de 1776, Kant sugeriu que a razão é a fonte das ilusões transcendentais, mas somente ao elaborar a sua teoria da razão, no período compreendido entre 1778 e 1780, extrai as conseqüências da distinção entre categorias e idéias, explicando por que a razão ultrapassa naturalmente o domínio da experiência possível e por que a ilusão transcendental é inevitável. Nesse período, ao estabelecer a tripartição da dialética transcendental, explica as origens dos paralogismos, da antinomia e do ideal da razão pura. Nas Reflexões desse período, Kant esboça apenas a introdução e o livro primeiro da dialética transcendental, que tratam da ilusão transcendental, dos usos lógico e puro da razão e das idéias transcendentais. Os esboços dos paralogismos, da antinomia e do ideal da razão pura não são objeto da sua atenção nesse momento.

Na R 5553, redigida entre 1778 e 1780, Kant retoma e aprofunda a distinção entre a razão e o entendimento. Enquanto o entendimento é a faculdade dos juízos, a razão é a faculdade das inferências. Se o entendimento em seu uso lógico é definido como a faculdade de julgar, a razão é a faculdade de raciocinar ou inferir. O raciocínio, também denominado silogismo, é o procedimento dedutivo da razão como faculdade de concluir mediatamente. Em todo silogismo parte-se de uma proposição dada, e através de uma proposiç̧ão intermediária, a conclusão é inferida. No seguinte exemplo, a razão procede progressivamente: Todos os homens são mortais. Todos os sábios são homens. Logo, todos os sábios são mortais. A conclusão é inferida como conseqüência da premissa maior por meio da condição da premissa menor. Mas há também a possibilidade de se proceder inversamente, isto é, regressivamente. Pode-se buscar a verdade da premissa maior, apresentando-a como conclusão de um pró-silogismo. Vejamos este segundo exemplo: Todos os animais são mortais. Todos os homens são animais. Logo, todos os homens são mortais. A nova premissa maior pode, por sua vez, ser objeto de um processo análogo e ser apresentada como conclusão de um pró-silogismo, e assim sucessivamente.

Nesse procedimento podemos constatar que a razão em seu uso lógico busca a condição geral de um juízo, ou seja, da conclusão deste. O raciocínio é o procedimento de inferir um juízo (conclusão) mediante a subsunção de sua condição (premissa menor) sob uma regra maior (premissa maior). Mas como essa regra está, por sua vez, submetida à mesma operação e deve buscar a condição da condição de um condicionado dado, o procedimento da razão em seu uso lógico a conduz à busca do incondicionado para 
o conhecimento condicionado do entendimento. Este é um princípio procedente da lógica formal, pois se a conclusão é dada, então deve ser possível elevar-se às premissas:

Assim como os sentidos estão em relação com o entendimento, o entendimento está em relação com a razão. Os fenômenos dos primeiros recebem do segundo a unidade do entendimento através de conceitos e os conceitos recebem na terceira faculdade a unidade da razão através das idéias (através de pró-silogismos um objeto mais remoto é encontrado, até que finalmente nem um outro mais possa ser encontrado...).

(...) A razão não pode referir-se aos objetos, senão aos conceitos do entendimento. Como um conceito da razão pode ser objetivo, se ele não expressa a (condição) da unidade da experiência (possível) (pelo qual nos são dados todos os objetos), mas apenas manifesta a unidade do conhecimento do entendimento? (...) A razão procura levar os conhecimentos do entendimento (juízos) às condições mais remotas; ainda assim, um tal conhecimento pode ser considerado condicionado: podemos dizer que a razão é um princípio do uso do entendimento para encontrar o incondicionado para o (na série do) condicionado. (R 5553, Ak. XVIII, 221-22)

Enquanto o entendimento, por intermédio das categorias, confere às representações sensíveis o caráter de objetividade, a razão confere unidade e sistematicidade aos conhecimentos do entendimento. A relação existente entre os fenômenos é de condicionado à sua condição, mas a razão busca o incondicionado para o conhecimento condicionado pela sensibilidade e pelo entendimento. Mediante o incondicionado, denominado idéia transcendental, o entendimento adquire a coerência consigo mesmo. Embora faça parte do interesse natural da razão teórica, a regressão do condicionado ao incondicionado não implica necessidade objetiva, mas subjetiva. Enquanto as categorias são condições de possibilidade da experiência e de seus objetos, estando, portanto, limitadas ao domínio da experiência possível, as idéias transcendentais - que são conceitos puros da razão e não têm na sensibilidade objetos que lhes correspondam - determinam, segundo princípios, o uso do entendimento na busca do conjunto total das experiências. Diz Kant: "Todos os conceitos de síntese são ou condições de possibilidade da experiência ou idéias. As idéias transcendentais não podem ter validade objetiva, mas como problemas necessários devem ser deduzidas" (R 5553, Ak. XVIII, 224). "Entendo por idéia", escreve Kant, "um conceito que é suficientemente fundado na razão, mas ao qual não pode ser dado objeto algum de uma experiência possível" (R 5553, Ak. XVIII, 226). E afirma: "A possibilidade das idéias é inegável, mas não podem ser compreendidas empiricamente; a idéia não é um conceptus dabilis, um conceito possível empiricamente" (R 4966, Ak. XVIII, 43). Salienta Kant:

Se eu admito que um conceito a priori tem um objeto, eu devo poder conhecer também tudo a priori, a condição que o conceito contém. Nada há de incerto e inde- 
cidível, e não obstante a razão contém as condições do uso empírico e todas as tentativas transcendentes são impossíveis e inúteis. Os conceitos transcendentes não são conceitos de objetos. São idéias. (R 4946, Ak. XVIII, 38)

Para ser fiel à arquitetônica da Crítica da razão pura, que está em processo de elaboração, não basta definir o termo idéia, é necessário também deduzi-la, concebendo-a num "sistema das idéias transcendentais" (R 5553, Ak. XVIII, 223). Kant deriva as três idéias da razão das três categorias de relação, porque "os conceitos de relação não são outra coisa que a unidade do condicionado e sua condição, e a razão eleva essa relação à condição, que é incondicionada" (R 5553, Ak. XVIII, 222). As idéias, como condições incondicionadas, podem, segundo Kant, ser apresentadas assim:

A condição incondicionada subjetiva do pensamento.

A condição incondicionada objetiva dos fenômenos.

A condição incondicionada objetiva de todos os objetos em geral. (R 5553, Ak. XVIII, 226)

Das três categorias de relação, as séries de pró-silogismos da razão originam três formas de inferências dialéticas. Os silogismos categórico, hipotético e disjuntivo correspondem, respectivamente, às seguintes categorias de relação: substância, causa e reciprocidade. Em cada um deles, a relação do condicionado com a condição é a relação do predicado com o sujeito (silogismo categórico), do efeito com a causa (silogismo hipotético) e da mútua exclusão entre as partes de um todo (silogismo disjuntivo). Esses três raciocínios dialéticos correspondem às três formas do conceito de incondicionado postuladas pelo princípio sintético a priori da razão pura, a saber: "A proposição: se o condicionado é dado, também é dada a série completa das condições, mediante a qual o condicionado é determinado" (R 5553, Ak. XVIII, 222-3). Ao relacionar o incondicionado com a atividade da razão, Kant encontra três formas de ilusão transcendental:

A primeira ilusão é aquela em que a unidade da apercepção, que é subjetiva, é tomada pela unidade do sujeito como uma coisa. A segunda: a determinação subjetiva da sensibilidade e sua condição são tomadas por um objeto. A terceira: a universalidade do pensamento, por meio da razão, é tomada pelo pensamento da totalidade das coisas. (R 5553, Ak. XVIII, 224)

Dessas três formas de ilusão, a que mais ocupa a atenção de Kant na Crítica da razão pura é a segunda, na qual trata a antinomia da razão pura; entretanto, a discussão das causas e conseqüências dela, nas Reflexões, só ocorre às vésperas da redação dessa obra.

A cosmologia é o ramo da metafísica especial que busca a totalidade absoluta das condições dos fenômenos, mas, ao tratar as antinomias já nas 
Reflexões, Kant apresenta quatro pares de inferências dialéticas relativas ao mundo, que correspondem aos quatro grupos de categorias, classificadas em matemáticas e dinâmicas. Da concepção do mundo como objeto de conhecimento, na perspectiva do realismo transcendental, decorre a formulação necessária de quatro pares de proposições opostas, cada par exposto na forma de tese e antítese, e cada uma delas é suscetível de demonstração.

Visto que as teses e as antíteses de cada uma das quatro antinomias podem ser demonstradas com todo o rigor e igualmente refutadas na perspectiva do realismo transcendental, Kant as apresenta deliberadamente, simulando um conflito da razão consigo mesma, não para se posicionar a favor de umas e contra outras, mas para verificar se o objeto da disputa não é ilusório. Esse procedimento é denominado por ele método cético:

As proposições transcendentais do entendimento puro são téticas, quando restritas à condição do fenômeno, isto é, às condições da sensibilidade sob as quais o objeto é dado. Mas quando tornam-se transcendentes, são, então, antitéticas e dão bela matéria ao método cético. A antitética transcendental provém da natureza da própria razão e não tem nada de acidental ou arbitrário. (R 4985, Ak. XVIII, 51-2)

\section{Conclusão}

Argumentei que os problemas da dialética transcendental estão ausentes em 1770, não sendo possível, portanto, a consciência do problema antinômico ter sido o fator que levou Kant a despertar do sonho dogmático. Ao criticar (na carta a Herz de 1772) o uso real do entendimento, isto é, a validade objetiva das representações intelectuais, Kant elabora o projeto da Crítica da razão pura. Até 1775, Kant nega a possibilidade da ontologia, esboçando os elementos principais da analítica transcendental: a dedução metafísica, a dedução transcendental e o esquematismo. A crítica da metafísica especial, que é um dos objetos da dialética transcendental, está ausente nesse momento. Somente entre 1778 e 1780 Kant elabora a tripartição da dialética transcendental em paralogismos, antinomia e ideal da razão, no entanto, a análise dos raciocínios dialéticos da razão pura só será objeto da atenção de Kant às vésperas da publicação da Crítica da razão pura.

LINHARES, O. B. Waking from dogmatic slumber. Trans/Form/Ação, (São Paulo), v.28(2), 2005, p.53-81.

- ABSTRACT: In this article I argue against the very diffused interpretation according to the year of 1769 represented a frontier in the formation of transcendental philosophy and that the Dissertation of 1770 corresponds to the first criti- 
cal text. The objective of this article is to investigate the origin of the antinomies in Reflections in the seventies. It doesn't mean to sketch the antinomies, so about them Kant is reticent in this period. They are object of his attention only the day before writing the Critique of pure reason. I deal with a few elements that will make possible their formulation and solution in Critique fo pure reason.

- KEYWORDS: transcendental analytic, transcendental dialetic, reason, understanding and antinomy.

\section{Referências bibliográficas}

AL-AZM, Sadik J. 1972: The origens of Kant's arguments in the antinomies. Oxford, Oxford, University Press.

ALLISON, Henry E. 1983: Kant's transcendental idealism. An interpretation and defense. New Haven/London, Yale University Press.

BAUMANNS, Peter 1978: „Kants mathematische Antinomien”. In: Allgemeine Zeitschrift für Philosophie, v. 12, pp. 23-40.

BECK, Lewis White 1996: Early german philosophie. Kant and his predecessors. Cambridge, Thoemmes Press.

1978a: "Lambert and Hume in Kant's Development from 1769 to 1772". In: Essays on Kant and Hume. New Haven/London, pp. 101-10.

1978b: "Did the sage of Königsberg have no dream?". In: Essays on Kant and Hume, New Haven/London, pp. 38-60.

1989: "Two ways of reading Kant's letter to Herz: Comments on Carl", In:

Kant's transcendental deduction. The three Critiques and the Opus Postumum. Editado por Eckart Forster. Stanford, California, Stanford University Press, pp. 21-28.

BEISER, Frederic C. 1992: "Kant's intellectual development: 1746-1781". In: The Cambridge companion to Kant. editado por Paul Guyer. Cambridge University Press, pp. 26-61.

CARL, Wolfgang 1989a: Der schweigende Kant. Die Entwürfe zu einer Deduktion der Kategorien vor 1781, Göttingen.

. 1989b: "Kant's first drafts of the deduction of the categories". In: Kant's transcendental deduction. The Three Critiques and the Opus Postumum. Editado e traduzido por Eckart Forster. Stanford, California, Stanford University Press, pp. 3-20.

CASSIRER, Ernst 1985: Kant, vida y doctrina. México, Fondo de Cultura Económica. 1986: El problema del conocimiento, II. Traducción de Wenceslao Roces, México. Fondo de Cultura Económica.

COFFA, Alberto 1991: The Semantic Tradition from Kant to Carnap. Cambridge.

ERDMANN, Benno 1878: Einleitung zu Immanuel Kant's Prolegomena zu einer künftigen Metaphysik, die als Wissenschaft wird auftreten können. Hg. und historisch erklärt von B. E. Leizpig, I-CXIV. 
FANG, Joong 1967: „Das Antinomienproblem im Entstehungsgang der Transzendentalphilosophie". In: Kant-Interpretationen. Münster.

GRAM, M. S. 1960: "Kant's First Antinomie”. The Monist, v. 51, pp. 499-518.

GUEROULT, Martial 1978: "La dissertation kantienne de 1770. Deux conférences". In: Archives de Philosophie, v. 41, pp. 3-25.

GUYER, Paul 1995: Kant and the claims of knowledge. Cambridge University Press.

1989: "The unity of reason: pure reason as practical reason in Kant's early conception of the transcendental dialectic". in: The Monist, v. 74, n 3, Illinois, pp. 139-167.

HAERING, Theodor 1910: Der Duisburg'sche Nachlass und Kants Kritizismus um 1775. Tübingen.

HINSKE, Norbert 1966: „Kants Begriff der Antinomie und die Etappen seiner Ausarbeitung". In: Kant-Studien, v. 56, 485-496.

1970: Kants Weg zur transzendentalphilosophie. Der dreissigjährige Kant. Stuttgart, Berlin, Köln, Mainz. Kohlhammer.

KANT, Immanuel 1766: Träume eines Geistersehers, erläutert durch Träume der Metaphysik. In: Kants Werke. Akademie Textausgabe, v. II, (1968), Berlin/New York.

1770: De mundi sensibilis atque intelligibilis forma et principiis. Tradução portuguesa de José Andrade: In: Kants Werke. Akademie Textausgabe, v. II, (1968) Berlin/New York. "Acerca da forma e dos princípios do mundo sensível e do mundo inteligível”. In: Textos pré-críticos, Rés-Editora, Porto.

1781-1787: Kritk der reinen Vernunft. Hamburg, Felix Meiner. 1990. Tradução portuguesa de Manuela Pinto dos Santos e Alexandre Fradique Morujão: "Crítica da Razão Pura". Lisboa, Fundação Calouste Gulbenkian.

1783: Prolegomena zu einer jeden künftigen Metaphysik, die als Wissenschaft wird auftreten können. In: Kants Werke. Akademie Textausgabe, v. IV, (1968), Berlin/New York. Tradução portuguesa de Artur Morão: "Prolegômenos a Toda Metafísica Futura", Lisboa, Edições 70.

1800: Logik. In: Kants Werke. Akademie Textausgabe, v. IX, (1968) Berlin/New York. Editada por Jäsche. Tradução brasileira de Guido Antônio de Almeida: "Lógica", Rio de Janeiro, Biblioteca Tempo da Ciência.

1926: „Kant's handschriftlicher Nachlass”, In: Kants gesammelte Schrifte, v. XVII, Editado por Erich Adickes, Berlin/Leipzig, Walter de Grunter \& CO.

1928: „Kant's handschriftlicher Nachlass”, In: Kants gesammelte Schrifte, v. XVIII, Editado por Erich Adickes. Berlin/Leipzig, Walter de Grunter \& CO.

1991: Correspondance. Tradução de Marie-Christine Challiol, Michèle Hamili, Valérie Séroussi, Nicolas Aumonier, Marc B. de Launay e Max Marcuzzi. Gallimard.

KREIMENDAHL, Lothar 1990: Kant-der Durchbruch von 1769. Köln.

LAYWINE, Alison 1993: Kant's early metaphisics and the origins of the critical philosophy. California, Ridgeview Publishing Company. 
LEBRUN, Gerard 1993: "O aprofundamento da Dissertação de 1770 na Crítica da razão pura". In: Sobre Kant. São Paulo, Iluminuras, pp. 37-50.

LOPARIC, Zeljko 1987. "Kant's dialectic". In: Nous, n. 21, 1987, pp. 573-93.

1990: "The logical struture of the first antinomy". In: Kant-Studien, v. LXXXI, N. 3, pp. 280-303.

2000: "A semântica transcendental de Kant". Campinas, CLE. (Coleção CLE, v. 29).

MARTIN, Gottfried 1955: "Kant's metaphysics and theory of science". Manchester, Manchester University Press.

PEREZ, Daniel Omar 2000: A predicação do ser. A análise kantiana no período précrítico. Uma aproximação lógico-semântica do texto Principiorum primorum cognitionis metaphysicae nova dilucidatio. Campinas, Comodecon IFCHUnicamp.

REICH, Klaus 1958: „Über das Verhältnis der Dissertation und der Kritik der reinen Vernunft und die Entstehung der kantischen Raumlehre." In: Kant (1958); De mundi sensibilis atque intelligibilis forma et principiis. Introdução à tradução alemã Hamburg, Felix Meiner. pp. VII-XVI.

ROBINSON, Lewis 1924: Contributions à l'Histoire de l'Évolution Philosophique de Kant. In: Revue de Metaphisique et de Morale, 3, pp. 269-353.

SCHMUCKER, Joseph 1974: „Zur entwicklungsgeschichtlichen Bedentung der Inauguraldissertation von 1770". In: Kant-Studien, v. 65, pp. 263-282.

1976: „Was entzündete in Kant das grosse Licht von 1769?”. In: Archiv für Geschichte der Philosophie, v. 58, pp. 393-434.

SMITH, Norman Kemp 1923: A Commentary to Kant's 'Critique of pure reason'. Macmillan.

STRAWSON, P. F., 1973: The bounds of Sense. An essay on Kant's Critique of Pure Reason. London, Methuen.

THEIS, R., 1982: Le Silence de Kant. Etude sur l'évolution de la pensée kantienne entre 1770 et 1781. In: Revue de métaphysique et morale, pp. 209-239.

TONELLI, Giorgio 1963: „Die Umwälzung von 1769 bei Kant.” In: Kant-Studien, v. 54 pp. 369-375.

VAIHINGER, Hans 1976: Commentar zu Kants Kritik der reinen Vernunft, II. New York/London, Garland Publishing.

VLEESCHAUWER, H. J. de 1938: Les antinomies kantiennes et la clavis universalis d'Arthur Collier. In: Mind Newseries.

1976: La déduction transcendentale dans l'oeuvre de Kant, I: La déduction transcendentale avant de la Critique de la raison pure. New York/London Garland Publishing. 